«Системні технології» 5 (130) 2020 «System technologies»

DOI 10.34185/1562-9945-5-130-2020-12

УДК 669.1:004.942:[532.54+519.63+66.069.84]

\title{
К.С. Красніков \\ МАТЕМАТИЧНЕ МОДЕЛЮВАННЯ ВАКУУМНОЇ ДЕГАЗАЦІЇ СТАЛІ У КОВШІ З АРГОННОЮ ПРОДУВКОЮ
}

Анотація. У статті подано математичну модель нестаціонарного процесу деазотації $i$ дегідрогенізація розплаву сталі у вакууматорі камерного типу з аргонною продувкою. Дегазація сталі за допомогою вакууму - поширена серед металургійних підприємств технологія, яка дає можливість досягати надзвичайно низької концентрації водню та азоту у металевому розплаві, що необхідно для підвищення якості сталевих виробів. $3 a$ відомою гіпотезою спочатку атоми газу знаходяться у розплаві у розчиненому стані. Бульбашки водню і азоту формуються з розчину на поверхні ковшової футерівки при умові достатньо низького феростатичного тиску металевого розплаву. Тиск, необхідний для появи бульбашки, визначається відповідно закону Сівертса. Значною мірою на дегазацію впливає і продувка аргоном, бульбашки якого збирають водень $і$ азот на своєму шляху, спливаючи через розплав. Також важливим завданням є зменшення тривалості дегазаціі для зберігання температури розплаву на достатньо високому рівні. Проведення чисельних досліджень означеного вище процесу на математичній моделі зменшує витрати часових і фінансових ресурсів, тому побудова моделі є актуальним завданням. Опис плину розплаву і газів у ковші здійснюється на основі законів збереження маси та вектору кількості руху суцільного середовища, що виправдано через дрібний розмір бульбашок і їх велику кількість. 3 огляду на складність пошуку аналітичного розв'язку нелінійних диференціальних рівнянь у часткових похідних у тривимірній постановці, пропонується використовувати метод центральних різниць, який має достатню точність і широко використовується для подібних задач. Обчислювати математичну модель пропонується у комп'ютерній програмі на мові С\#, яка має широкі можливості по програмуванню алгоритмів. Програмний додаток дозволить оцінити вплив інтенсивності аргонної продувки, а також глибини розплаву, на ступінь його дегазації, що може бути використано при впровадженні технологічних рекомендацій у виробництво сталі.

Ключові слова: вакууматор камерного типу, дегазація металевого розплаву, суцільне багатоскладове середовище, рівняння Нав'є-Стокса.

Постановка проблеми. Пошук доцільних технологічних параметрів камерного вакуумування, яке широко використовується сьогодні для

(C) Красніков К.С., 2020

102

ISSN 1562-9945 (Print)

ISSN 2707-7977 (Online) 
«Системні технології» 5 (130) 2020 «System technologies»

досягнення високої якості сталі, в промислових або лабораторних умовах $\epsilon$ коштовним i, з огляду на високу температуру розплаву та умови перебігу процесу вакуумування, не достатньо інформативним. В той же час математичне моделювання дозволяє одержати детальний опис системного стану означеного процесу при значно меншій вартості проведення дослідів, кількість яких сягає сотні через вимогу достовірності.

Аналіз останніх досліджень і публікацій. На сьогоднішній день існує багато досліджень процесу вилучення водню та азоту. У роботі [1] автори надають інформацію про джерела азоту та водню в сталі, про транспортування азоту через шлак за законом Фіка та оцінюють ступінь десорбції азоту. Також наведено перелік параметрів експерименту, що використовуються з під час ковшових операцій, наприклад, вага металу, вага доданого коксу, час перемішування, швидкість потоку інертного газу, товщина шару шлаку, загальний вміст водню та азоту. Автори пропонують порівняння експериментальних і розрахункових концентрацій за формулами.

Багато математичних моделей дегазації азоту використовують рівняння у частинних похідних, наприклад, представлена в роботі [2] математична модель використовує зв'язані динаміку рідини та багатофазний потік для прогнозування розподілів азоту та водню в рідкій сталі. Відповідні рисунки показують поле швидкості та концентрацію газу.

Автори роботи [3] оцінюють параметри бульбашок для дегазації у стовпі аргону, який підіймається з дна ковша. Їх модель розглядає поверхневий натяг рідкої сталі, середній розмір бульбашки, який впливає на деазотацію. Припускається постійна кількість пузирів і постійна температура сталі $\left(1600^{\circ} \mathrm{C}\right)$.

У дисертації [4, с. 33-36] наведено графічну залежність вмісту водню від тривалості дегазації. Встановлено, що кінетику дегазації водню та азоту можна прогнозувати за допомогою реакції першого порядку. Вказується, що достатньо 10 хвилин, щоб зменшити вміст водню та азоту до необхідного рівня. Автор зауважує, що кисень та сірка впливають на видалення азоту, тому їх вміст повинен бути нижче 80 ppm. 


\section{«Системні технології» 5 (130) 2020 «System technologies»}

Автор роботи [5, стор. 17-19, 63-75] надає деталі молекулярної реакції газу водню та азоту з їх коефіцієнтами дифузії у рідкому залізі. Автор робить помітки про бульбашки СО, які часто утворюються під час вакуумування, перемішують розплав та являють собою "малі вакуумні камери" для газів H2 і N2. Така ж ситуація виникає, коли під час продування виникають тисячі бульбашок аргону. Автор подає вирази констант розчинності для Н2, N2 та залежність концентрації Н в сталі від загального обсягу необхідного аргону та маси сталі в ковші. Також автор описує основні конструктивні особливості дегазаційних установок та технологічні варіанти сталевого вакуумування в ковші.

Робота [6] присвячена дослідженню десорбції азоту з розплавленої сталі на експериментальному апараті. Швидкість десорбції N2 визначається рівняннями першого порядку за допомогою трьох стадій: перенесення азоту з розплаву в інтерфейс; хімічна реакція утворення молекул N2; передача азоту від інтерфейсу до об'ємного газу.

Автори [7] розглядають 2D математичне моделювання розкислення 3 трьома пов'язаними процесами: течією розплаву з турбулентністю; кінетика коалесценції; динамічний кисневий баланс. Наявність шлаку на вільній поверхні не розглядається і передбачено стаціонарні умови процесу. Автори відобразили графічну залежність кількості часток включень від тривалості.

Серед існуючих методів вакуумної дегазації широко використовуються два методи: заглиблення спеціального рециркуляційного дегазатора у розплав і розміщення ковша у вакуумному дегазаторі.

Огляд літературних джерел виявив декілька особливостей перебігу вакуумної дегазації:

1) Розміщення ковша у вакуумному дегазаторі [8, с. 12-13] є суттєво легшим ніж організація роботи рециркуляційного способу вакуумної дегазації. Також у порівнянні $з$ дегазацією у камері рециркуляційний спосіб має вищу інвестиційну і операційну коштовність (вимагає нагрівання перед заглибленням у розплав і потребує більше простору над ковшем), але дозволяє легше керувати кипінням, брати проби температури 
«Системні технології» 5 (130) 2020 «System technologies»

і розплаву під вакуумом, розміщувати відеокамеру для спостереження поверхні розплаву [9].

2) Бульбашки інертного газу добре забирають водень і азот з розплаву, виносячи їх крізь товщу розплаву на поверхню. Врахування газу у рівняннях моделей відбувається за допомогою трьох способів: квазіоднофазного із зменшеною густиною розплаву; комбінування Ейлеревого опису з Лангражевим для прогнозуванням траєкторії руху бульбашок без їх взаємодії і з врахуванням наявності газу під час обчислення рівнянь Нав’є-Стокса для фази суцільного середовища розплаву; Ейлерів опис двох взаємопроникаючих фаз суцільного середовища і з постійним розміром бульбашок. На початку дегазації з продуванням аргоном швидкість вивільнення водню через бульбашки аргону у п’ять разів перевищує швидкість його вивільнення через поверхню металевого розплаву.

3) В існуючих роботах стисливість суміші розплав-газом часто не враховується, що може спричинити неадекватність результатів чисельних досліджень.

4) Вміст розчиненого водню і азоту у металевому розплаві визначається за законом Сівертса. Відповідно до нього при зменшенні тиску в розчині (по декільком причинам) створюються сприятливі умови виникнення бульбашок водню і азоту на твердих поверхнях ковша, на включеннях всередині розплаву або на бульбашках аргону під час продування.

Формулювання мети дослідження. Метою роботи є визначення залежності дегазації розплаву від інтенсивності продування і глибини розплаву на основі законів збереження у вигляді нелінійних диференціальних рівнянь у часткових похідних для подальшого визначення раціональних параметрів процесу.

Викладення основного матеріалу дослідження. Основні припущення для математичної моделі:

1) Поверхня розплаву є плоска.

2) Тіло розплаву має форму усіченого конуса (рис. 1), тіло зберігає постійний об'єм у ковші та є в’язкою рідиною Ньютона. 
«Системні технології» 5 (130) 2020 «System technologies»

3) Водень і азот розчиняються в розплаві відповідно до закону Сiвертса і формування пузирів відбувається на поверхні ковшової футерівки в залежності від феростатичного тиску розплаву.

4) Вакуумне наближення використовується для врахування стисливості газу.

5) Розчинені гази вивільняються з розплаву завдяки пузирям аргону зі швидкістю, пропорційною концентрації аргону та відповідного газу.

6) Газові пузирі представляються суцільним середовищем, яке рухається наскрізь розплав із постійною швидкістю, припускаючи миттєве іiї досягнення.

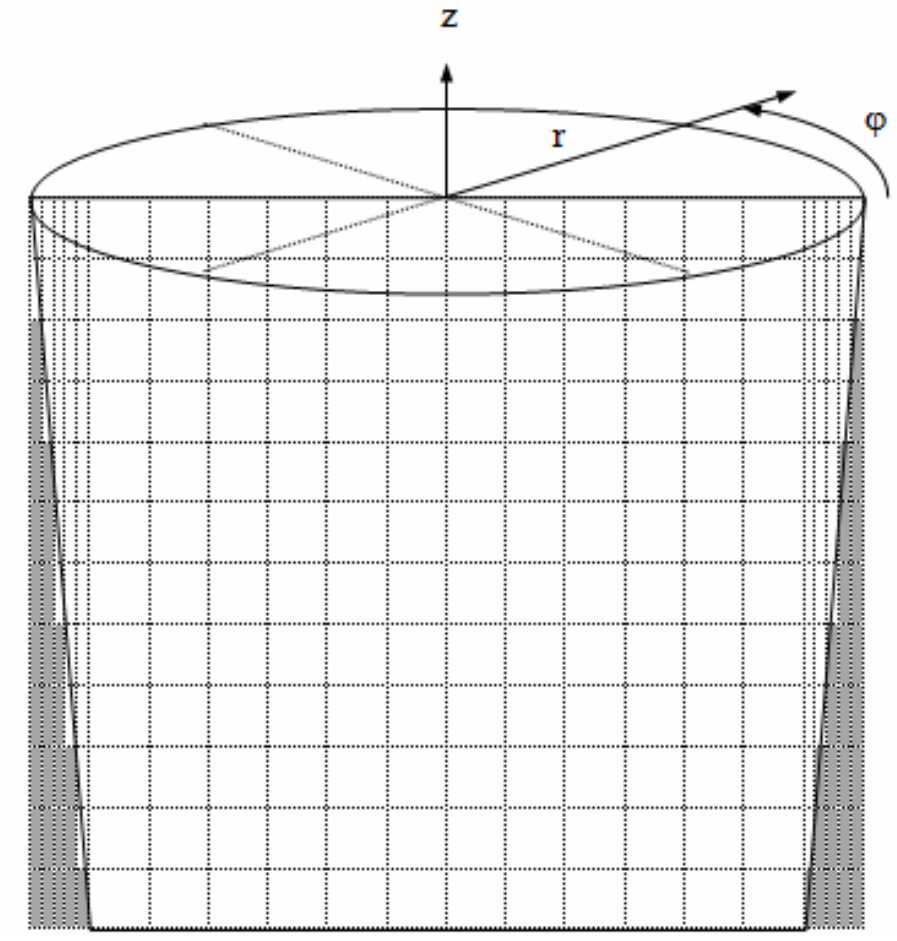

Рисунок 1 - Розрахункова область з урахуванням конусності ковша

Розплав представлений багатоскладовим суцільним середовищем з барицентричною швидкістю і з урахуванням ефективної стисливості газу [10]. Рівняння руху континууму виражається за допомогою наближення Буссинеска для плавучості:

$$
\frac{d \vec{v}}{d t}=-\vec{\nabla} \widetilde{p}+v_{e} \Delta \vec{v}+\zeta_{e}^{\prime} \vec{\nabla}(\vec{\nabla} \cdot \vec{v})-\alpha \vec{g},
$$

106 
«Системні технології» 5 (130) 2020 «System technologies»

$$
\begin{aligned}
& \vec{\nabla} \cdot \vec{v}=-\Phi, \\
& \Phi=\vec{\nabla} \cdot\left(\alpha \vec{w}_{a}^{c}+D_{\alpha} \vec{\nabla} \alpha\right)-\Phi_{\alpha}, \\
& \Phi_{\alpha}=\psi_{\alpha}-\alpha \zeta \rho_{0} \vec{g} \vec{v}_{\alpha},
\end{aligned}
$$

Розрахунок газового руху враховує поле швидкості розплаву та стисливість середовища [10]:

$$
\begin{gathered}
\frac{\partial \alpha}{\partial t}+\vec{\nabla} \cdot\left[\alpha\left(\vec{v}+\vec{w}_{a}^{c}\right)\right]=\vec{\nabla} \cdot\left(D_{\alpha} \vec{\nabla} \alpha\right)+\psi_{\alpha}-\zeta \rho_{0} \vec{g} \cdot\left[\alpha\left(\vec{v}+\vec{w}_{a}^{c}\right)+D_{\alpha} \vec{\nabla} \alpha\right]+\psi_{\mathrm{HN}}, \\
\psi_{\mathrm{HN}}=\max \left(H-K_{H} \sqrt{p_{H_{2}}}, 0\right)+\max \left(N-K_{N} \sqrt{p_{N_{2}}}, 0\right) \\
\frac{\partial H}{\partial t}+\vec{\nabla} \cdot(H \vec{v})=\vec{\nabla} \cdot\left(D_{H} \vec{\nabla} H\right)-k_{H} H \alpha-\max \left(H-K_{H} \sqrt{p_{H_{2}}}, 0\right) \\
\frac{\partial N}{\partial t}+\vec{\nabla} \cdot(N \vec{v})=\vec{\nabla} \cdot\left(D_{N} \vec{\nabla} N\right)-k_{N} N \alpha-\max \left(N-K_{N} \sqrt{p_{N_{2}}}, 0\right)
\end{gathered}
$$

де $v_{e}$ - ефективна (з врахуванням турбулентної) в’язкість середовища; $\zeta^{\prime}-$ друга в'язкість, що виникає через стисливість; $\vec{w}_{a}^{c}-$ колективна швидкість газового поля; $D_{\alpha}, D_{H}, D_{N}-$ коефіцієнти ефективного розсіювання відповідно аргону, водню і азоту; $k_{H}, k_{N}-$ коефіцієнти пропорційності захвату атомів газу пузирями; $\psi_{\alpha}-$ джерело об'ємної частки аргону поблизу фурми; $K_{H}, \mathrm{~K}_{N}$ - коефіцієнти розчинності поділеної на активність відповідних газів у розплаві; $p_{H}, p_{N}$ - тиск, враховуючи і феростатичний і всередині бульбашки $\left(p_{a t m}+\gamma h+2 \sigma / r\right)$.

Рівняння доповнюються граничними умовами. Для поля швидкості: на поверхні розплаву, на стінках ковша і на вісі ковша - умова непротікання і вільного ковзання. Для поля аргону: на поверхні розплаву вільне перенесення у повітря. Для полів азоту і водню: на поверхні розплаву - вивільнення з розплаву сталі.

Для чисельного розв’язання системи рівнянь (1)-(7) використовується циліндрична система координат і спеціально розроблений метод [10].

Висновки. Побудовано математичну модель, яка містить рівняння збереження вектору кількості руху металевого розплаву та об'ємної частки газів у ньому, доповнюючи рівняння граничними умовами для розв’язання. Циліндрична система координат добре відповідає геометрії 


\section{«Системні технології» 5 (130) 2020 «System technologies»}

задачі. Пропонується використовувати метод центральних різниць для чисельного розв’язання рівнянь. Обчислювати математичну модель пропонується у комп’ютерній програмі на мові С\#, яка має широкі можливості по програмуванню алгоритмів. Програмний додаток дозволить оцінити вплив потужності аргонної продувки, а також глибини розплаву на ступінь його дегазації, що може бути використано при впровадженні технологічних рекомендацій у виробництво сталі.

\section{ЛИТЕРАТУРА / ЛІТЕРАТУРА}

1. Fruehan R.J., Misra S. Hydrogen and nitrogen control in ladle and casting operations. Report, Pittsburgh, PA. - 2005.

DOI: https://doi.org/10.2172/1216251.

2. Shan Yu, Miettinen J. and others. Mathematical modeling of nitrogen removal from the vacuum tank degasser. WILEY-VCH Verlag GmbH \& Co. KGaA, Weinheim: Steel research int. 86 (2015) No. 5.

3. Gobinath R., Vetrivel Murugan R. Denitrogenation model for vacuum tank degasser. International Conference on Advances in Metallurgy, Materials and Manufacturing. IOP Publishing Ltd. - 2018.

4. Steneholm K. The effect of ladle treatment on steel cleanness in tool steels. Doctoral thesis, Stockholm. - 2016.

5. Валуев Д. В. Внепечные и ковшовые процессы обработки стали в металлургии. Уч. пособие. 2-е испр. изд. / Д.В. Валуев; Юргинский технологический институт Томск: Изд-во Томского политехнического университета, 2010. - 202c.

6. Yamanaka R., Ogawa K. and others. Denitrogenization mechanism from molten steel by flux treatment. ISIJ International, Vol. 32 (1992), No. 1, pp. 136-141.

7. Shirabe K., Szekely J. A mathematical model of fluid flow and inclusion coalescence in the $\mathrm{R}-\mathrm{H}$ vacuum degassing system. Transactions ISIJ, Vol. 23, 1983. pp. $465-474$.

8. Shan Yu. Numerical modeling of dehydrogenation and denitrogenation in industrial vacuum tank degassers. A doctoral dissertation for the degree of Doctor of Science (Technology), Aalto University School of Chemical Technology, Espoo, Finland, 3 October, - 2014. 50 pp.

9. Zulhan Z., Schrade C. Vacuum Treatment of Molten Steel: RH (Rurhstahl Heraeus) versus VTD (Vacuum Tank Degasser) // SEAISI Conference and Exhibition, Kuala Lumpur. - 2014. p. 7. 
«Системні технології» 5 (130) 2020 «System technologies»

10. Огурцов А. П., Самохвалов С. $Є$. Математичне моделювання теплофізичних процесів у багатофазних середовищах / Київ: Наукова думка. 2001. -409 c.

\section{REFERENCES}

1. Fruehan R.J., Misra S. Hydrogen and nitrogen control in ladle and casting operations. Report, Pittsburgh, PA. - 2005.

DOI: https://doi.org/10.2172/1216251.

2. Shan $\mathrm{Yu}$, Miettinen J. and others. Mathematical modeling of nitrogen removal from the vacuum tank degasser. WILEY-VCH Verlag GmbH \& Co. KGaA, Weinheim: Steel research int. 86 (2015) No. 5.

3. Gobinath R., Vetrivel Murugan R. Denitrogenation model for vacuum tank degasser. International Conference on Advances in Metallurgy, Materials and Manufacturing. IOP Publishing Ltd. - 2018.

4. Steneholm K.. The effect of ladle treatment on steel cleanness in tool steels. Doctoral thesis, Stockholm. - 2016.

5. Valuev D. V. Out-of-furnace and ladle steel treatment processes in metallurgy. Tutorial. 2 correct. edition / D.V. Valuev; Yurga Institute of technology, TPU affiliate: Publisher of Tomsk polytechnic university, 2010. - 202c.

6. Yamanaka R., Ogawa K. and others. Denitrogenization mechanism from molten steel by flux treatment. ISIJ International, Vol. 32 (1992), No. 1, pp. 136-141.

7. Shirabe K., Szekely J. A mathematical model of fluid flow and inclusion coalescence in the $\mathrm{R}-\mathrm{H}$ vacuum degassing system. Transactions ISIJ, Vol. 23, 1983. pp. $465-474$.

8. Shan Yu. Numerical modeling of dehydrogenation and denitrogenation in industrial vacuum tank degassers. A doctoral dissertation for the degree of Doctor of Science (Technology), Aalto University School of Chemical Technology, Espoo, Finland, 3 October, - 2014. 50 pp.

9. Zulhan Z., Schrade C. Vacuum Treatment of Molten Steel: RH (Rurhstahl Heraeus) versus VTD (Vacuum Tank Degasser) // SEAISI Conference and Exhibition, Kuala Lumpur. - 2014. p. 7.

10. Ogurtsov A.P., Samokhvalov S.E. Mathematical modeling thermophysical processes in multiphase mediums / Kyiv: Naukova dumka. - 2001. - 409 p. 
«Системні технології» 5 (130) 2020 «System technologies»

\section{Математическое моделирование вакуумной дегазации стали \\ в ковше с аргонной продувкой}

В статье представлена математическая модель нестационарного процесса деазотации и дегидрогенизации расплава стали в вакууматоре камерного типа с аргонной продувкой. Дегазация стали при помощи вакуума - распространенная среди металлургических предприятий технология, которая дает возможность достигать необычно низкие концентрации водорода и азота в металлическом расплаве, что необходимо для повышения качества стальных изделий. Проведение вычислительных опытов на предложенной математической модели уменьшает затраты временных и финансовых ресурсов, поэтому построение модели является актуальной задачей. Программное приложение позволит оценить влияние интенсивности аргонной продувки, а также глубины расплава, на степень его дегазации, что может быть использовано при внедрении технологических рекомендаций в производство стали.

Mathematical modelling vacuum degassing of steel in argon-stirred ladle

The article presents a mathematical model of a non-stationary process of denitrogenation and dehydrogenation of steel melt in vacuum chamber with argon stirring. Vacuum degassing is a technology that is widely used in metallurgical plants to achieve extremely low concentrations of hydrogen and nitrogen in the metal melt, which is needed to improve the quality of steel products. According to the well-known hypothesis, initially the gas in the melt is in the dissolved state. Hydrogen and nitrogen bubbles are formed from a solution on the surface of the ladle lining provided that the pressure of metal melt is sufficiently low. The pressure required for the bubble to appear is determined in accordance with Sieverts' law. To a large extent, the degassing is also affected by the argon stirring, when bubbles collect hydrogen and nitrogen in their paths, floating through the melt and flying off the free surface. It is also important to reduce the duration of degassing to keep the melt temperature at a sufficiently high level, as well as to speed up overall process. Conducting numerical studies of the above process on a mathematical model reduces the cost of time and financial resources, so building a model is an actual task. The description of the melt flow and gases in the ladle is based on the mass and impulse conservation laws for a continuous medium, which is justified by the small size of the bubbles and their large number. Given the complexity of finding the analytic solution of nonlinear differential equations in partial derivatives in three-dimensional formulation, it is proposed to use the central difference method, which is sufficiently accurate and widely used for similar problems. It is proposed to implement the mathematical model in a C\# computer program, because that language has sufficient programming capabilities, including parallelization of computation. The software application will allow evaluating the influence of the intensity of argon stirring, as well as the depth of the melt, on the degree of degassing, which can be used in the implementation of technological recommendations in the production of steel.

Красников Кирилл Сергеевич - к.т.н., ст. преподаватель кафедры программного обеспечения Днепровского государственного технического университета.

Красніков Кирило Сергійович - к.т.н., ст. викладач кафедри програмного забезпечення Дніпровського державного технічного університету.

Krasnikov Kyrylo Serhiiovych - PhD, senior lecturer at systems software department of Dniprovskyi state technical university. 